\title{
Chronic disease of the ascending aorta
}

\section{Surgical treatment and long-term results}

Between January 1979 and December 1991, we operated on 339 patients for chronic disease of the ascending aorta. The operation was elective in all. Endocarditis and its sequelae have been excluded. Thirty-one patients had a previous operation on the ascending aorta or the aortic valve; 268 patients had aneurysms of the ascending aorta without dissection; 71 had chronic aortic dissections, of whom 33 had a preexistent aneurysm. The patients included 272 men and 67 women. Mean age was $53.58 \pm 7$ years. Eight percent of the patients had clinical stigmata of Marfan's disease. A tubular graft replacement was used in 7 patients, a tubular graft and valve replacement in 72 patients, and a composite valve graft replacement with reattachment of the coronary arteries using a $8 \mathrm{~mm}$ Dacron graft was performed in 260 patients. Concomitant procedures were used in 74 patients: coronary artery bypass grafts in 25 , mitral valve replacement in 9 , and aortic arch reconstruction in 40 . The 30-day mortality rate was $7.6 \%(n=26)$. For the whole group, multivariate analysis using stepwise logistic regression showed that operative risk factors were concomitant coronary artery bypass grafting, age (increased), aortic valve regurgitation, and previous cardiac surgery. Follow-up was conducted in 303 patients, and risk factors for late mortality were studied. Long-term survival was $59.6 \% \pm 3.7 \%$ at 9 years. It was $67 \% \pm 3.5 \%$ at 9 years for patients without aortic arch reconstruction and $56 \% \pm 4.5 \%$ for patients with aortic arch reconstruction $(p=0.0018)$. Reoperation was needed in 14 patients. Actuarial freedom from reoperation was $90 \% \pm 0.2 \%$ at 9 years for all the patients. Only one patient with composite valve graft replacement and reattachment of the coronary arteries had required reoperation for problems related to this procedure. This technique is used routinely by our team, especially in patients with large chronic aneurysms, dissected or not, and in those who had previous operations. The long-term results are good. (J THORAC CardiovasC Surg 1994;108:747-54)

F. Jault, MD, P. Nataf, MD, A. Rama, MD, M. Fontanel, CS, E. Vaissier, MD, A. Pavie, MD,

V. Bors, MD, C. Cabrol, MD, and I. Gandjbakhch, MD, Paris, France

$\mathrm{T}_{\text {he }}$ he purposes of our data are to analyze retrospectively the results (30-day mortality rate, its risk factors, longterm survival, and rate of reoperation) of surgery in patients with chronic disease of the ascending aorta and to focus on the long-term results of composite valve graft replacement with reattachment of the coronary arteries by an $8 \mathrm{~mm}$ Dacron graft, as previously described by our team. ${ }^{1}$

From the Department of Thoracic and Cardiovascular Surgery, Pitie's Hospital, Paris, France.

Received for publication Oct. 6, 1993.

Accepted for publication April 19, 1994.

Address for reprints: F. Jault, Cardiovascular Unit, Pitie's Hospital, 93, Boulevard de l'Hôpital, 75013 Paris, France.

Copyright $\stackrel{1}{ } 1994$ by Mosby-Year Book, Inc.

$0022-5223 / 94 \$ 3.00+0 \quad 12 / 1 / 57172$

\section{Methods and patients}

Between January 1979 and December 1991, 339 patients were operated on for chronic disease of the ascending aorta: 268 had aneurysmal disease without dissection and 71 had chronic aortic dissection, of whom 33 had preexistent aneurysm. Aortic dissection was considered chronic when the interval between the onset of the acute symptoms and the operation exceeded 3 weeks.

The intimal tear was localized in 69 patients on the ascending aorta and in 2 patients on the arch. In 40 patients, the aortic arch was included in the repair because of severe dilatation of the false channel. The operation was elective in all the patients. Patients with sequelae of endocarditis or with diffuse disease of the distal descending and abdominal aorta at the time of operation were excluded.

The group included 272 men and 67 women. Mean age was $53.8 \pm 7$ years (Fig. 1). Eight percent of patients $(n=27)$ had clinical stigmata of Marfan's disease. Thirty-one patients (9.7\%) had had a previous operation on the ascending aorta or 


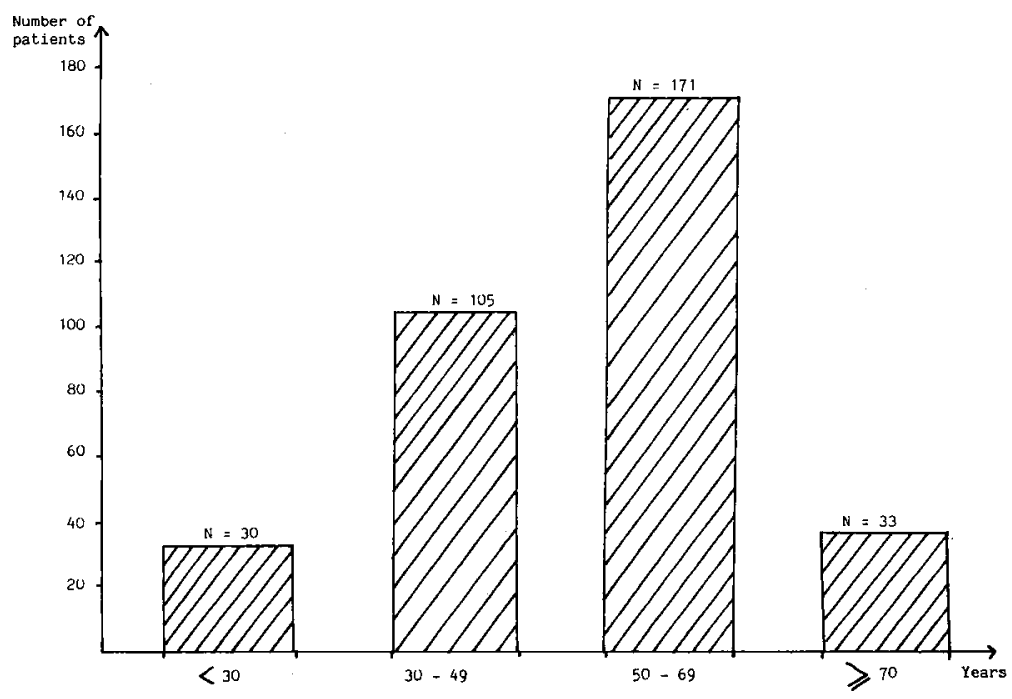

Fig. 1. Age of patients $(n=339)$.

the aortic valve. Seventy-one patients had hypertension. Surgery was performed most commonly because of aortic incompetence, because of the importance of the dilatation of the false channel in case of dissection, or because of the size of the aneurysm ( $>5$ $\mathrm{cm}$ ).

Seventy-one patients were in class I of the New York Heart Association (NYHA), 129 in class II, 127 in class III, and 2 in class IV. Preoperative neurologic symptoms were present in 4 patients. Cardiothoracic ratio was less than 0.5 in 56 patients, between 0.5 and 0.6 in 229 patients, and greater than 0.6 in 54 patients.

Coronary arteriography was performed in $165^{\prime \prime}$ patients because of age or angina. Concomitant surgical procedures were performed in 74 patients: coronary artery bypass grafts in 25 patients, mitral valve replacement in 9, and aortic arch reconstruction in 40 patients; 33 of the 40 reconstructions were hemiarch distal graft anastomoses.

Statistical analysis. Standard methods incorporating the BMDP statistical software package (Los Angeles, Calif.) were used: Univariate (Pearson $\chi^{2}$ test) and multivariate (stepwise logistic regression-BMDPLR) analyses were used to identify significant predictors of mortality rate. The checklist of the variables is shown in the appendix. Kaplan-Meier survival curves and their comparison with the Wilcoxon test were used for analysis of long-term survival. The stepwise Cox proportional hazard model was used for the late mortality analysis.

Operative technique. When the aortic sinus and valve were not involved or had been successfully replaced in an earlier operation, a tubular graft replacement was performed ( 7 cases). When the aortic valve was stenotic or incompetent and the sinus segment was normal, separate valve replacement or resuspension of the valve and tubular graft replacement were performed ( 72 cases). Most of the patients were treated by excision and end-to-end anastomosis of the graft to the aorta.

When the sinus segment of the aorta was dilated (annuloaortic ectasia, dissection with preexisting aneurysm of the ascending aorta, previously unsuccessful replacement, 260 cases), we used the inclusion wrap technique. A composite valve graft replacement with reattachment of the coronary arteries by an $8 \mathrm{~mm}$ Dacron graft was performed. A perigraft right atrial fistula was created in all cases. This technique has been previously described. ${ }^{1}$ Myocardial protection was provided by systemic hypothermia at $27^{\circ} \mathrm{C}$ with cold crystalloid cardioplegia and since January 1989 with cold blood cardioplegia.

When aortic arch reconstruction was needed, we used partial circulatory arrest with perfusion of the supraaortic branches and profound hypothermia as previously described. ${ }^{2}$ Brachiocephalic arteries were dissected, and atriofemoral cannulation and cardiopulmonary bypass were established. The femoral arterial line was connected to the cerebral line by the use of a Y-shaped connector. Cannulas were inserted into the innominate and the left common carotid arteries (or into both the carotid arteries) and linked to the cerebral line. Ascending aortic replacement was performed under hypothermia at $22^{\circ} \mathrm{C}$ as usual. At the end of the procedure, the brachiocephalic arteries were clamped. Selective cold blood perfusion $\left(18^{\circ} \mathrm{C}\right)$ of the carotid arteries was started while the femoral arterial line was clamped. The aortic arch was repaired. If the aorta was dissected at the level of the distal anastomosis, the two cylinders were joined with resorcine formol glue. Before the completion of the distal anastomosis on the arch, the femoral clamp was removed and air was removed from the aorta and from the heart. Cerebral perfusion was discontinued, and the carotid arteries were unclamped.

The aortic arch was repaired in 40 patients. The supraaortic branches were implanted into the graft individually in 6 patients, with an aortic button including the origin of the branches in 1 patient. An obliquely cut prosthetic graft was sewn into the concavity of the aortic arch in 33 patients. Concomitant coronary artery bypass grafts were performed in 25 patients. The proximal vein graft anastomoses were performed to the aorta distal to the graft. In 9 patients, the mitral valve was replaced because of mitral regurgitation. Three hundred two mechanical and 10 biologic aortic prostheses were inserted, and 3 suspensions of aortic commissures were performed. The mean duration of aortic clamping was $81 \pm 24$ minutes ( 13 to 176 minutes), 
and the mean duration of cardiopulmonary bypass was $122 \pm$ 31.5 minutes ( 32 to 300 minutes).

\section{Results}

Operative mortality rate ( 30 days). Overall 30 -day mortality rate was $7.6 \%(n=26)$. All patients were discharged from the hospital at this time. Operative mortality was $9.8 \%$ when the aorta was dissected $(n=7)$ and $7 \%$ when the aorta was not dissected ( $n=5)$. It was $12.5 \%$ for the 40 patients who had aortic arch reconstruction $(n=5)$ and $6 \%$ for the 217 patients who had composite valve graft replacement alone, without concomitant bypass grafting $(n=13)$.

The causes of death in order of frequency were hemodynamic failure (17 patients), stroke (6 patients), sepsis (2 patients), and pulmonary insufficiency (1 patient). Four patients $(15 \%)$ had multiple causes of death.

Univariate analysis of 30-day mortality is shown in Table I. Seven variables emerged as independent predictors of 30-day mortality for all the patients by multivariate analysis (Table II): concomitant coronary artery bypass grafting, age (increased), aortic valve regurgitation, previous cardiac operation, gender (female), duration of aortic clamping, and duration of cardiopulmonary bypass. For the patients with composite valve graft replacement alone, independent risk factors for 30-day mortality were age (increased), Marfan's disease, duration of aortic clamping, previous cardiac operation, and chronic aortic dissection (Table III).

Morbidity. Early reoperation for hemorrhage was required in $4.5 \%$ of the patients, $23 \%$ of patients required inotropic support, and $10.9 \%$ required prolonged ventilatory support. The overall risk of perioperative stroke was $4.7 \%(n=16)$. Six patients died of this complication. Among the 40 patients with aortic arch reconstruction, only 1 died of perioperative stroke. No patient had a permanent neurologic deficit.

Follow-up. Ten patients were lost to follow-up. Excluding 30-day mortality, 303 patients were followed up from 18 months to 14 years. Follow-up was completed in August 1993. Median follow-up was 1678 patientyears. Follow-up information was available by correspondence with both the patient and the referring cardiologist. All the patients were asked to undergo chest radiography, color flow Doppler echocardiography, and, in case of poor imaging, transesophageal echocardiography. An appropriate questionnaire was completed and the results were analyzed by one of us. Patients with Marfan's disease were asked to undergo computed tomographic or magnetic nuclear imaging.

Patients with mechanical prostheses received warfarin and aspirin ( $100 \mathrm{mg} /$ day $)$. There have been 70 late deaths
Table I. Univariate analysis of 30-day mortality for all the patients

\begin{tabular}{lc}
\multicolumn{1}{c}{ Variable } & $\mathrm{p}$ Value \\
\hline Age & $0.0180^{*}$ \\
Gender & $0.0478^{*}$ \\
Previous cardiac operation & 0.5923 \\
NYHA class & $0.0236^{*}$ \\
Cardiothoracic ratio & 0.5844 \\
Marfan syndrome & 0.4836 \\
Hypertension & 0.8232 \\
Preoperative stroke & $0.0014^{*}$ \\
Chronic aortic dissection & 0.4355 \\
Concomitant coronary artery bypass & $0.0014^{*}$ \\
Concomitant mitral valve replacement & 0.3808 \\
Aortic arch repair & 0.2705 \\
Aortic insufficiency & 0.1481 \\
Duration of aortic clamping & 0.1915 \\
Duration of CPB & 0.0816 \\
\hline
\end{tabular}

$C P B$, Cardiopulmonary bypass.

${ }^{*} p$ Value is significant.

(19 patients were 70 years of age or older at the time of death). The causes of death are listed in Table IV and were confirmed by autopsy in 56 cases. Nine patients with composite valve graft replacement died of unknown causes, 3 suddenly. No autopsy was done in these 9 patients.

Univariate analysis of late mortality for all the patients is shown in Table V and multivariate analysis (Cox model) in Table VI. Independent risk factors for late mortality were higher NYHA functional class, preoperative neurologic symptoms, aortic arch repair, mean pump time, and mean aortic clamping time. For the patients with a composite valve graft alone, risk factors were higher NYHA functional class, Marfan's disease, increased age, previous cardiac operation, and cardiothoracic ratio (Table VII).

Actuarial survival (operative mortality included) of all the patients was $59.6 \% \pm 3.7 \%$ at 9 years (Fig. 2). Dissection of the aorta had no statistically significant impact on actuarial survival (Fig. 3), but aortic arch reconstruction did (Fig. 4): survival was $67.1 \% \pm 3.5 \%$ at 9 years among the patients without aortic arch reconstruction and $50.06 \% \pm 8.8 \%$ at 9 years among the patients with aortic arch reconstruction $(p=0.0018)$. The actuarial survival of the 212 patients with composite valve graft replacement alone (operative mortality included) was $66.3 \% \pm 4.5 \%$ at 9 years (versus $48.4 \% \pm 6.4 \%$ for the 117 other patients, $p=0.01$ ) (Fig. 5).

Fourteen patients $(4.2 \%)$ underwent reoperation, with 2 operative deaths. One patient was operated on for an abdominal aortic aneurysm 6 years after cardiac surgery. Five patients were reoperated on because of aortic pros- 
Table II. Variables independently related to 30-day mortality in a stepwise logistic regression (BMDPLR model) for all the patients

\begin{tabular}{|c|c|c|c|c|c|}
\hline Step & Variable & $\begin{array}{l}\text { Degree of } \\
\text { freedom }\end{array}$ & $\begin{array}{c}B i- \\
\text { coefficient }\end{array}$ & $\begin{array}{c}F \\
\text { (Fisher) }\end{array}$ & $\mathrm{p}$ Value \\
\hline 1 & Concomitant coronary bypass grafting & 1 & 0.817 & 11.85 & 0.0006 \\
\hline 2 & Age & 1 & 0.043 & 0.78 & 0.0169 \\
\hline 3 & Aortic valve regurgitation & 1 & 0.955 & 3.76 & 0.0534 \\
\hline 4 & Previous cardiac operation & 1 & 0.526 & 3.06 & 0.0813 \\
\hline 5 & Gender & 1 & 0.385 & 2.79 & 0.0959 \\
\hline 6 & Duration of aortic clamping & 1 & -0.016 & 2.97 & 0.0859 \\
\hline \multirow[t]{2}{*}{7} & Duration of CPB & 1 & -0.034 & 5.59 & 0.0187 \\
\hline & Intercept & & -4.244 & & \\
\hline
\end{tabular}

$C P B$, Cardiopulmonary bypass.

Table III. Variables independently related to 30-day mortality in a stepwise logistic regression for the patients with composite valve graft replacement alone

\begin{tabular}{|c|c|c|c|c|c|}
\hline Step & Variable & $\begin{array}{l}\text { Degree of } \\
\text { freedom }\end{array}$ & $\begin{array}{c}B i- \\
\text { coefficient }\end{array}$ & $\begin{array}{c}F \\
\text { (Fisher) }\end{array}$ & $\mathrm{p}$ Value \\
\hline 1 & Age & 1 & 0.084 & 8.87 & 0.0032 \\
\hline 2 & Marfan's disease & 1 & 1.400 & 12.75 & 0.0004 \\
\hline 3 & Duration of aortic clamping & 1 & 0.028 & 4.32 & 0.0390 \\
\hline 4 & Previous cardiac operation & 1 & 0.922 & 7.47 & 0.0068 \\
\hline \multirow[t]{2}{*}{5} & Chronic aortic dissection & 1 & 0.765 & 4.22 & 0.0414 \\
\hline & Intercept & & -5.670 & & \\
\hline
\end{tabular}

Table IV. Causes of late deaths $(\mathrm{n}=70)$

\begin{tabular}{lc}
\hline \multicolumn{1}{c}{ Unknown } & $14^{*}$ \\
\hline AIDS & 6 \\
Endocarditis & 10 \\
Stroke & 7 \\
Myocardial failure & 10 \\
$\quad$ Chronic myocardial failure & 7 \\
$\quad$ Myocardial infarction & 3 \\
Aortic dissection & 3 \\
Sudden death & $8 \dagger$ \\
Hemorrhage & 2 \\
Cancer & 8 \\
Suicide & 2
\end{tabular}

AIDS, Acquired immunodeficiency syndrome.

*Including six patients with composite valve grafts.

$\dagger$ Including three patients with composite valve grafts.

thesis complications: early thrombosis in 1 , endocarditis in 2 ( 1 death), and biologic valve deterioration in 2 . One patient was reoperated on for late mitral valve insufficiency and died of myocardial failure. Six patients who had previous aortic dissection were reoperated on for persistent dissection of the abdominal aorta or the remaining thoracic aorta. Only 1 patient underwent reoperation related to the composite graft; the persistence of the fistula created between the perigraft space and the right atria was cured successfully.

The probability of freedom from reoperation was
Table V. Univariate analysis of late mortality for all patients

\begin{tabular}{lc}
\hline \multicolumn{1}{c}{ Variable } & $\mathrm{p}$ Value \\
\hline Age & $0.0284^{*}$ \\
Gender & 0.9588 \\
Previous cardiac operation & 0.0522 \\
NYHA class & 0.2012 \\
Cardiothoracic ratio & 0.1762 \\
Marfan's disease & 0.3127 \\
Hypertension & 0.9257 \\
Preoperative stroke & $0.0389^{*}$ \\
Chronic aortic dissection & $0.0232^{*}$ \\
Concomitant coronary artery & 0.1906 \\
bypass grafting & \\
Concomitant mitral valve replacement & 0.2390 \\
Aortic arch repair & $0.0011^{*}$ \\
Aortic insufficiency & 0.7066 \\
Duration of aortic clamping & 0.1605 \\
Duration of CPB & $0.0005^{*}$ \\
\end{tabular}

$C P B$, Cardiopulmonary bypass. $\% p$ Value is significant.

${ }^{*} p$ Value is significant.

$90 \% \pm 0.2 \%$ at 9 years for all the patients (Fig. 6). Risk factors for late reoperation for the whole group were age (decreased), hypertension, and higher NYHA functional class (Table VIII).

Two hundred thirty-one patients are alive; 160 had composite valve graft replacement alone. Analysis of color flow Doppler echography in these 160 patients showed 


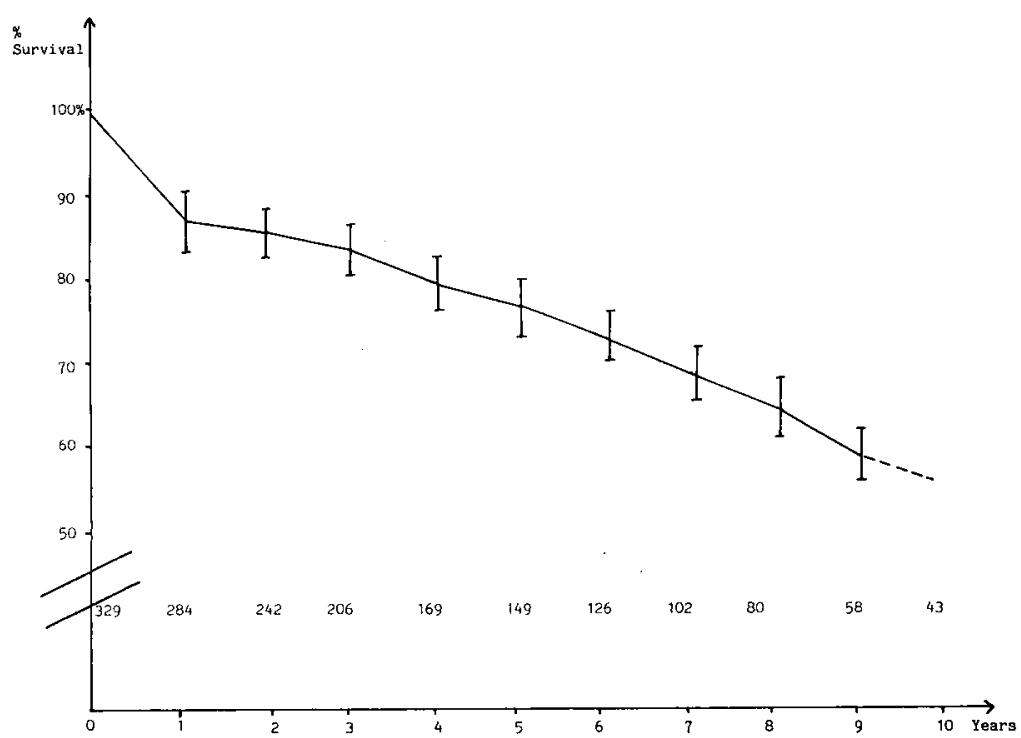

Fig. 2. Actuarial survival of all patients (operative mortality included) $(n=329)$. Numbers indicate patients alive and in follow-up at start of interval. Vertical bars indicate standard error.

Table VI. Variables independently related to late mortality in a stepwise logistic regression (Cox model) for all patients

\begin{tabular}{|c|c|c|c|c|}
\hline Step & Variable & Bi-coefficient & $x^{2}$ & $\mathrm{p}$ Value \\
\hline 1 & NYHA class & 0.3732 & 10.64 & 0.0011 \\
\hline 2 & $\begin{array}{l}\text { Preoperative neurologic } \\
\text { symptoms }\end{array}$ & 1.7123 & 8.7 & 0.0032 \\
\hline 3 & Aortic arch reconstruction & 0.5412 & 5.41 & 0.0200 \\
\hline 4 & Duration of $\mathrm{CPB}$ & 0.0146 & 3.38 & 0.0659 \\
\hline 5 & Duration of aortic clamping & -0.0159 & 5.89 & 0.0153 \\
\hline
\end{tabular}

$C P B$, Cardiopulmonary bypass.

Table VII. Variables independently related to late mortality in a stepwise logistic regression (Cox model) for patients with composite valve graft replacement alone

\begin{tabular}{clccc}
\hline Step & \multicolumn{1}{c}{ Variable } & Bi-coefficient & $\chi^{2}$ & $\mathrm{p}$ Value \\
\hline 1 & NYHA class & 0.3732 & 9.22 & 0.0024 \\
2 & Marfan's disease & 1.7123 & 4.86 & 0.0276 \\
3 & Age & 0.5412 & 7.30 & 0.0037 \\
4 & Previous cardiac surgery & 0.0146 & 3.38 & 0.0069 \\
5 & Cardiothoracic ratio & -0.0159 & 3.81 & 0.0509
\end{tabular}

no left-to-right shunt at the right atrial level and no pseudoaneurysm at the suture lines. Magnetic nuclear imaging or computed tomography was performed in only 15 patients with overt Marfan's syndrome. In 1 patient an abdominal aortic aneurysm has developed 7 years after the operation.

\section{Comments}

Some points are still being discussed in the surgical therapy for chronic disease of the ascending aorta: how to repair the aortic root (open or inclusion wrap technique, direct or indirect reattachment of the coronary arteries), how to protect the brain in case of aortic arch reconstruction, and how to improve early and late results.

Since 1976, when the aortic root has been involved, we have routinely performed a composite valve graft using the inclusion wrap technique with reattachment of the coronary arteries by an $8 \mathrm{~mm}$ Dacron graft. Composite valve graft replacement avoids recurrent aneurymal for- 


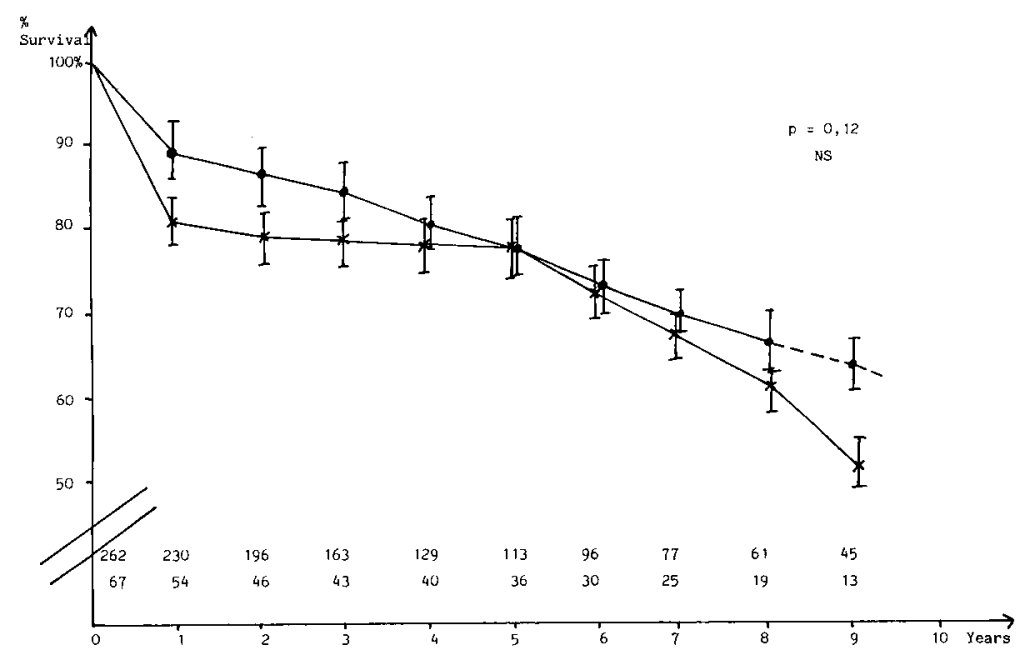

Fig. 3. Actuarial survival of 262 patients without chronic aortic dissection (•) and of 67 patients with chronic dissection $(\mathrm{x})$.

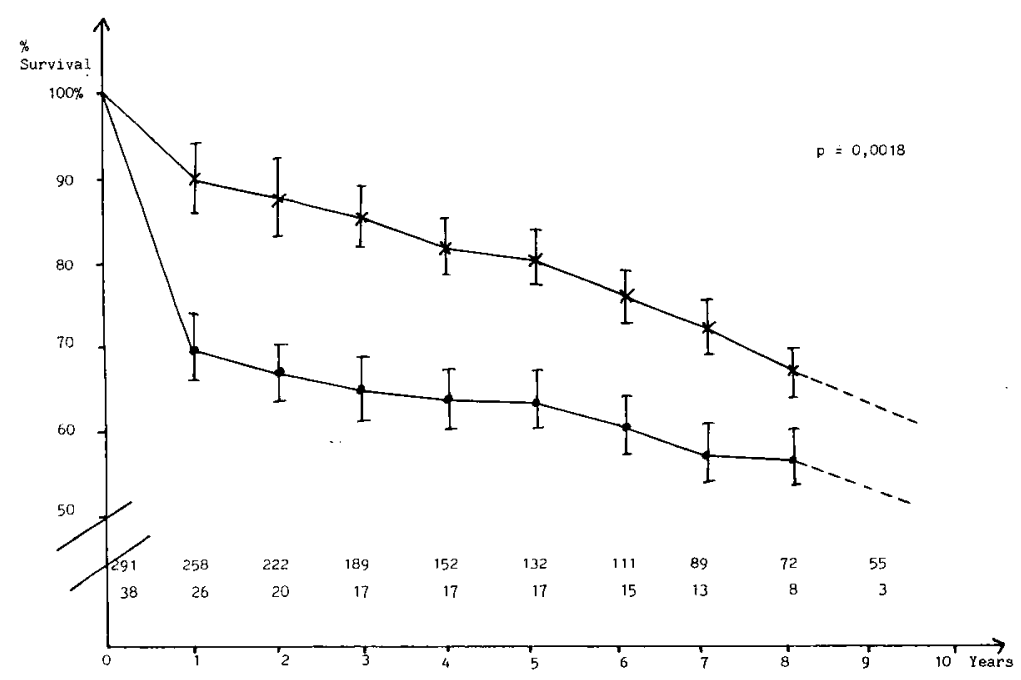

Fig. 4. Actuarial survival of 291 patients (x) without arch reconstruction and of 38 patients with aortic arch reconstruction $(\bullet)$.

Table VIII. Variables independently related to reoperation in a stepwise logistic regression (Cox model) for all patients

\begin{tabular}{clccc}
\hline Step & Variable & Bi-coefficient & $\chi^{2}$ & $\mathrm{p}$ Value \\
\hline 1 & Age & -0.0367 & 4.78 & 0.0288 \\
2 & Hypertension & 1.3412 & 4.33 & 0.0374 \\
3 & NYHA class & 0.6430 & 2.84 & 0.0919 \\
\hline
\end{tabular}

mation of the proximal aorta, leading to reoperation. These reoperations still carry a high mortality rate. ${ }^{3}$

We always use the inclusion wrap technique..$^{4-6}$ The incidence of early reoperation for bleeding is low, $4.5 \%$ in this series, and can be compared to the rate of $2 \%$ in Kouchoukos' series with the open technique. ${ }^{7}$ No reoper- ation for pseudoaneurysm of the ascending aorta was necessary in our patients.

Reattachment of the coronary arteries with an $8 \mathrm{~mm}$ Dacron graft seems to us, as to others, ${ }^{8,9}$ safer and easier to do than direct reattachment or reattachment by buttons of aorta surrounding the coronary arteries, as 


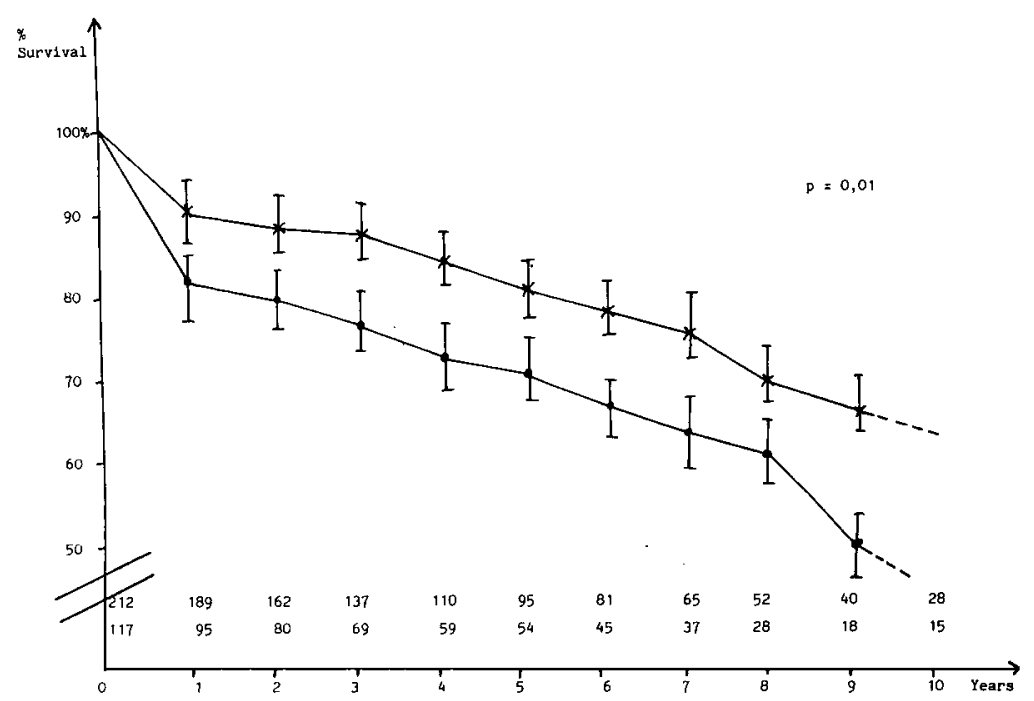

Fig. 5. Actuarial survival of 212 patients with composite valve graft without bypass surgery or arch construction (x) versus 117 other patients $(\bullet)$.

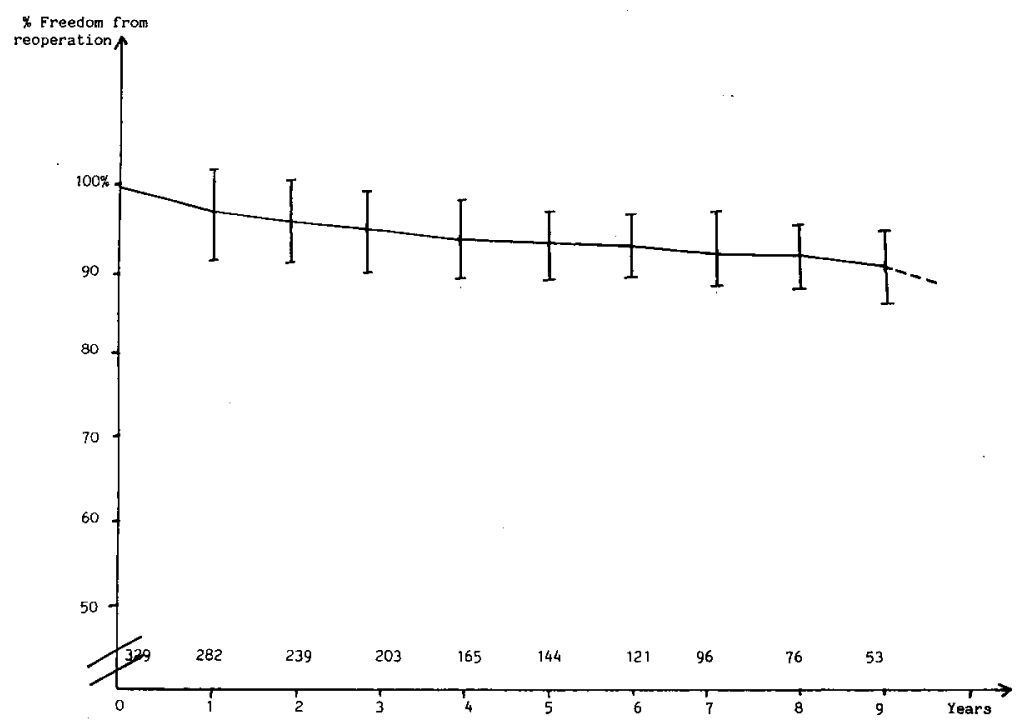

Fig. 6. Probability of freedom from reoperation for all 329 patients.

performed by other teams. ${ }^{7,10,11}$ Pseudoaneurysms at the coronary ostia were reported by Taniguchi, ${ }^{12}$ Kouchoukos, ${ }^{13}$ and their coworkers with these techniques. We think that the use of an $8 \mathrm{~mm}$ Dacron graft avoids this complication, as shown by routine coronary arteriography performed at the beginning of our experience. ${ }^{1}$ The perigraft right atrial fistula closed in all but 1 case, in which reoperation was necessary. Nine patients who received composite grafts died suddenly or of unknown cause. No autopsy was done. The possibility of false aneurysms or fistulas resulting in death cannot, of course, be excluded in the patients.
Aortic arch reconstruction is always indicated when aneurysmal disease involves the arch, when the false lumen of the dissection extends into the arch, or when the intimal tear is localized on the arch ( 2 cases in this series). Total hypothermic circulatory arrest ${ }^{14}$ seems to us to result in more neurologic complications. Griepp and associates ${ }^{15}$ reported a $5.6 \%$ rate of permanent neurologic injury in 87 patients. We prefer partial hypothermic arrest with selective cannulation of the head branches. ${ }^{16}$ One patient in our group of 40 patients had a stroke leading to death.

The 30 -day mortality rate was $7.6 \%$ for all the patients 
and $6 \%$ for the patients with composite valve graft replacement alone. Galloway ${ }^{5}$ and Kouchoukos ${ }^{7}$ and their associates reported similar operative mortality rates-respectively, $5.3 \%$ and $5 \%$. Variables suggestive of an increase in operative mortality rate by univariate analysis are, in this series, concomitant coronary artery bypass grafting, increased age, higher NYHA class, and gender (female). Multivariate analysis also indicates that concomitant coronary artery bypass grafting and increased age are the main risk factors, as shown by others. ${ }^{17}$

Overall survival is not so good in patients who undergo surgical intervention for chronic disease of the ascending aorta: $48 \%$ at 12 years for Kouchoukos ${ }^{7}$ and $57 \%$ at 7 years for Crawford. ${ }^{5}$ In this series, overall survival is $59.6 \% \pm 3.7 \%$ at 9 years for all the patients and $66.3 \% \pm 4.5 \%$ at 9 years for patients with composite graft alone (operative mortality included).

No predominant cause of late death was detected in this series. The factors that increase risk are indicative of a greater than usual complexity of the disease, as shown by univariate analysis: mean pump time, aortic arch repair, chronic aortic dissection, and increased age. In the Cox model the variables that have independent influence are almost the same.

\section{Conclusion}

In aortic root involvement, composite valve grafting performed by the inclusion wrap technique, with reattachment of the coronary arteries by a Dacron graft, offers good long-term results. The major operative risk factor is concomitant coronary artery bypass grafting. Late mortality remains a concern. Long-term survival is still poor for patients with previous cardiac surgery, with overt Marfan's syndrome, with chronic aortic dissection, with aortic arch repair, and in a high NYHA functional class.

We thank J. P. Darlon and M. Nectoux for their statistical assistance.

\section{REFERENCES}

1. Cabrol C, Pavie A, Mesnildrey $P$, et al. Long-term results with total replacement of the ascending aorta and reimplantation of the coronary arteries. J THORAC CARDIOVASC SURG 1986;91:17-25.

2. Nataf P, Bracamontes L, Gandjbakhch I, Pavie A, Cabrol C. Cardioplegia for aortic root replacement. In: Engelman RM, Levitsky S: A text book of cardioplegia for difficult problems. Mt. Kisco, NY: Futura, 1992.

3. Crawford ES, Crawford JL, Safi HJ, Coselli JS. Redo operations for recurrent aneurysmal disease of the ascending aorta and transverse arch. Ann Thorac Surg 1985; 40:439-55.

4. Kouchoukos N. Aortic graft-valve (composite) replace- ment at 20 years: Wrap or no wrap? Shunt or no shunt? Ann Thorac Surg 1989;48:615-6.

5. Galloway AC, Colvin SB, La Mendola CL, et al. Ten-year operative experience with 165 aneurysms of the ascending aorta and aortic arch. Circulation 1989;80:(Suppl):I24956.

6. Galloway AC, Colvin SB, Grossi EA, et al. Surgical repair of type A aortic dissection by the circulatory arrest-graft inclusion technique in sixty-six patients. J THORAC CARDIOVASC SURG 1993;105:781-90.

7. Kouchoukos N, Wareing TH, Murphy SF, Perillo JB. Sixteen-year experience with aortic root replacement. Ann Surg 1991;214:308-20.

8. Coselli JS, Crawford ES. Composite valve graft replacement of aortic root using separate Dacron tube for coronary artery reattachment. Ann Thorac Surg 1989;47:558-65.

9. Crawford ES, Svensson LG, Coselli JS, Safi HJ, Hess KR. Surgical treatment of aneurysm and/or dissection of the ascending aorta, transverse aortic arch, and ascending aorta and transverse aortic arch. J ThORAC CARDIOvasC SURG 1989;98:659-74.

10. Guilmet D, Diaz F, Bachet J, et al. Replacement of the ascending aorta with reimplantation of the coronary arteries: results in 81 cases. Arch Mal Coeur 1988;81:1185-92.

11. Gott VL, Pyeritz RE, Cameron DE, Greene PS, McKusick VA. Composite graft repair of Marfan's aneurysm of the ascending aorta: results in 100 patients. Ann Thorac Surg 1991;52:38-45.

12. Taniguchi $K$, Nakano S, Matsuda $H$, et al. Long term survival and complications after composite graft replacement for ascending aortic aneurysm associated with aortic regurgitation. Circulation 1991;84(Suppl):III31-9. .

13. Kouchoukos NT, Marshall WG Jr, Wedige-Stecher TA. Eleven-year experience with composite graft replacement of the ascending aorta and aortic valve. J THORAC CARDIOVASC SURG 1986;92:691-705.

14. Cooley DA. Experience with hypothermic circulatory arrest and the treatment of aneurysms of the ascending aorta. Semin Thorac Cardiovasc Surg 1991;3:166-70.

15. Griepp RB, Ergin MA, Lansman SL, Galla JD, Pogo G. The physiology of hypothermic circulatory arrest. Semin Thorac Cardiovasc Surg 1991;3:188-93.

16. Gandjbakhch I, Jault F, Vaissier E, et al. Surgical treatment of chronic aortic dissections. Eur J Cardiothorac Surg 1990;4:466-71.

17. Lytle BW, Mahfood SS, Cosgrove DM, Loop FD. Replacement of the ascending aorta: early and late results. J Thorac Cardiovasc Surg 1990;99:651-8.

\section{Appendix}

Variables entered into risk factors analyses: age, gender, previous cardiac operation, NYHA functional class (I to IV), cardiothoracic ratio, Marfan's syndrome, hypertension, preoperative neurologic symptoms, chronic aortic dissection, concomitant coronary artery bypass grafting, concomitant mitral valve replacement, aortic arch reconstruction, aortic valve regurgitation, duration of aortic clamping, and duration of cardiopulmonary bypass. 